\title{
A study of catalytic behaviour of aromatic additives on the photo-Fenton degradation of phenol red
}

\author{
ABHILASHA JAIN, SAVITRI LODHA, P B PUNJABI, V K SHARMA and \\ SURESH C AMETA* \\ Photochemistry and Solar Energy Laboratory, Department of Chemistry, University College of Science, \\ M L Sukhadia University, Udaipur 313002 \\ e-mail: jainabhilasha5@gmail.com
}

MS received 27 February 2009; 9 June 2009; accepted 26 June 2009

\begin{abstract}
The present study describes the photochemical degradation of phenol-red using photoFenton reaction. The progress of the reaction has been monitored spectrophotometrically. The effect of various organic additives e.g. hydroquinone, resorcinol and catechol on the rate of photodegradation has been observed. The effect of variation of various parameters such as $\mathrm{pH}$, concentration of dye, $\mathrm{Fe}^{3+}$ ion and additives, amount of $\mathrm{H}_{2} \mathrm{O}_{2}$, and light intensity on the rate of photodegradation was also observed. A tentative mechanism of the reaction has been proposed.
\end{abstract}

Keywords. Photo-Fenton; spectrophotometrically; phenol-red; hydroquinone; resorcinol and catechol.

\section{Introduction}

Now-a-days nature is facing a serious problem of environmental pollution due to multifarious activities of human beings. One of the most pressing problems is water pollution. Photochemical degradation of dyes employing Fenton reagent provides a newer method for the treatment of waste water containing dye effluents. Fenton's reagent is an established reagent for the degradation of dye but the main drawback of the reagent is that the reaction becomes very slow after the consumption of $\mathrm{Fe}^{2+}$ ions, whose regeneration by $\mathrm{Fe}^{+3}$ ions is very slow, whereas in photo-Fenton reaction, $\mathrm{Fe}^{2+}$ ions are readily regenerated from $\mathrm{Fe}^{3+}$ ions with an additional requirement of light. This makes the process cyclic in nature and photochemical degradation proceeds smoothly. Thus ferric chloride was used instead of ferrous salts.

Fenton reaction is an effective method to treat organic pollutants in waste water. ${ }^{1-4}$ Simple Fenton reaction involves the formation of hydroxyl and perhydroxy radicals. ${ }^{5-7}$

Degradation of various organic compounds e.g. 2,4-dichlorophenoxy acetic acid, $p$-dichlorobenzene and chlorobenzene; salicylic acid, poly(ethylene glycol), etc. by Fenton and photo-Fenton reagent

\footnotetext{
*For correspondence
}

has been reported. ${ }^{8-12}$ Degradation of malachite green by Fenton's reagent catalysed by various aromatic additives was examined by Chen et al. ${ }^{13}$ Sedlak et $a l^{14}$ examined the photocatalytic effects of $\mathrm{Fe}$ (III) compounds on the hydroxylation of benzoic acid by hydrogen peroxide initiated by UVradiation. Walling ${ }^{15}$ studied intermediates in the reaction of Fenton's type reagents. A comparative study of Fenton's, photo-Fenton's and other related reagents on the degradation of various types of compounds e.g. dyes, resorcinol, etc. has been done. ${ }^{16,17}$ Huang et $a l^{18}$ reported the removal of citrate and hypophosphite binary components using Fenton, photo-Fenton and electro-Fenton processes. Methomyl degradation in aqueous solutions by Fenton's reagent and the photo-Fenton system is observed by Tamimi et al. ${ }^{19}$ Optimizing the treatment of landfill leachate by conventional Fenton and photo-Fenton processes has been carried out by Hermosilla et $a l^{20}$ Papić et $a l^{21}$ studied the decolourization and mineralization of commercial reactive dyes by using homogeneous and heterogeneous Fenton and UV/Fenton processes, whereas the treatment of wastewater by Fenton and photoFenton processes has been investigated by different groups of researchers. ${ }^{22-24}$

Although photo-Fenton reaction is a useful tool for the degradation of dyes as well as organic com- 
pounds but the major drawback is the slow rate of degradation, so it is important and necessary to find out some better and suitable modifications to increase the efficiency and applications of this reagent. Zakharov and Kumpman ${ }^{25}$ observed the inhibiting and chemiluminescent properties of benzoic acid and acetyl salicylic acid in the presence of Fenton reagent. Sulphate, chloride and fluoride ions inhibit the process because these ions reduce the reactivity of ferric ions through coordination to form less reactive complexes. ${ }^{26}$ Effect of fulvic acid on $\mathrm{Fe}$ (II) oxidation by hydrogen peroxide has been studied by Voelker and Sulzberger. ${ }^{27}$

The effect of quinones on the free radical processes of oxidation and fragmentation of hydroxylcontaining organic compounds has been investigated by Shadyro et al. ${ }^{28}$ In the present work, the effect of various organic additives on the rate of photoFenton degradation of phenol red was investigated and the main emphasis is given to determine the conditions where these additives show the maximum rate of reaction. An attempt has also been made to explain their catalytic behaviour.

\section{Experimental}

All solutions were prepared in doubly distilled water. $0.0886 \mathrm{~g}$ of phenol red was dissolved in $250.0 \mathrm{~mL}$ of doubly distilled water so that the concentration of dye solution was $1.0 \times 10^{-3} \mathrm{M}$, which was used as stock solution. $30 \mathrm{~mL}$ reaction mixture was prepared by mixing all reagents one by one; whereas in case of hydroquinone system; the concentrations of dye, ferric chloride and hydroquinone were kept $8.33 \times 10^{-5} \mathrm{M}, 2.33 \times 10^{-5} \mathrm{M}$ and $2.00 \times 10^{-4} \mathrm{M}$, respectively and $0.2 \mathrm{~mL}$ of $\mathrm{H}_{2} \mathrm{O}_{2}$ was added to the solution. For the typical run of catechol system, $30 \mathrm{~mL}$ reaction mixture was prepared, which contained $8.33 \times 10^{-5} \mathrm{M}$ dye, $2.33 \times 10^{-5} \mathrm{M}$, ferric chloride and $1.67 \times 10^{-5} \mathrm{M}$ catechol and $0.1 \mathrm{~mL}$ of $\mathrm{H}_{2} \mathrm{O}_{2}$ was added to the solution. In case of resorcinol system, the $30 \mathrm{~mL}$ reaction mixture has $1.00 \times 10^{-4} \mathrm{M}$ dye, $2.33 \times 10^{-5} \mathrm{M}$ ferric chloride and $3.33 \times 10^{-5} \mathrm{M}$ resorcinol and $0.1 \mathrm{~mL}$ of $\mathrm{H}_{2} \mathrm{O}_{2}$ was added to the solution. These specified concentrations have been chosen on the basis of optimization of each reagent's concentration and these optimum values are the ones established constant when other parameter was changed.

For the irradiation the solution was placed under the $200 \mathrm{~W}$ tungsten lamp, which emitted the radia- tions of visible range. The light intensities at various distances from the lamp were measured with the help of a solarimeter (CEL, Model SM 201). A water filter (a petridish, full of water) was used to cutoff thermal radiations. A digital $\mathrm{pH}$ meter (Systronics, Model 335) was used to measure the $\mathrm{pH}$ of the system. The $\mathrm{pH}$ of the solutions was adjusted by the addition of previously standardized $0 \cdot 1 \mathrm{M}$ sulfuric acid and $0 \cdot 1 \mathrm{M}$ sodium hydroxide solutions. All the solutions were kept at room temperature. The progress of the photochemical reactions was observed by measuring the absorbance at regular time intervals of $10 \mathrm{~min}$ with the UV-visible spectrophotometer (Systronics Model 106). Hydroquinone (E. Merck), resorcinol (E. Merck). $\mathrm{FeCl}_{3}$ (E. Merck) catechol (CDH) and phenol red (Hi-media) was used as received commercially from the company specified in parenthesis. Hydrogen peroxide (E. Merck), concentration $30 \%$, w $/ v$ ) was been used.

\section{Results and discussion}

An aliquot of $3.0 \mathrm{~mL}$ was taken out from the reaction mixture at regular time intervals $(10 \mathrm{~min}$.) and the absorbance was measured at $\lambda_{\max }=430 \mathrm{~nm}$. It was observed that absorbance of the solution decreases with increasing time of exposure, indicating a decrease in concentration of phenol red.

The results are presented graphically in figures 1A-C. It was observed that absorbance of the solution decreases with increasing time of exposure, indicating a decrease in concentration of dye phenol red. A plot of $1+\log$ [O.D.] or $2+\log$ [O.D.] versus time was found to be linear and it follows pseudo-first order kinetics. The rate constant was measured with the expression:

$$
k=2 \cdot 303 \times \text { Slope. }
$$

It was observed that reaction was completed in two stages. The first stage has an induction period; may be for the generation of the ${ }^{\circ} \mathrm{OH}$ radicals but during this time, a small decrease in O.D. has been observed, which may be attributed to simple photochemical degradation of dye. After this slow stage, a major decrease in O.D. has been observed, which seems to be the second stage of photo-Fenton degradation, where ${ }^{\circ} \mathrm{OH}$ radicals act as oxidizing species for the degradation of dye. At the later stage of reaction, a lag period has also been observed, where the rate of reaction again slows down. The effect of 

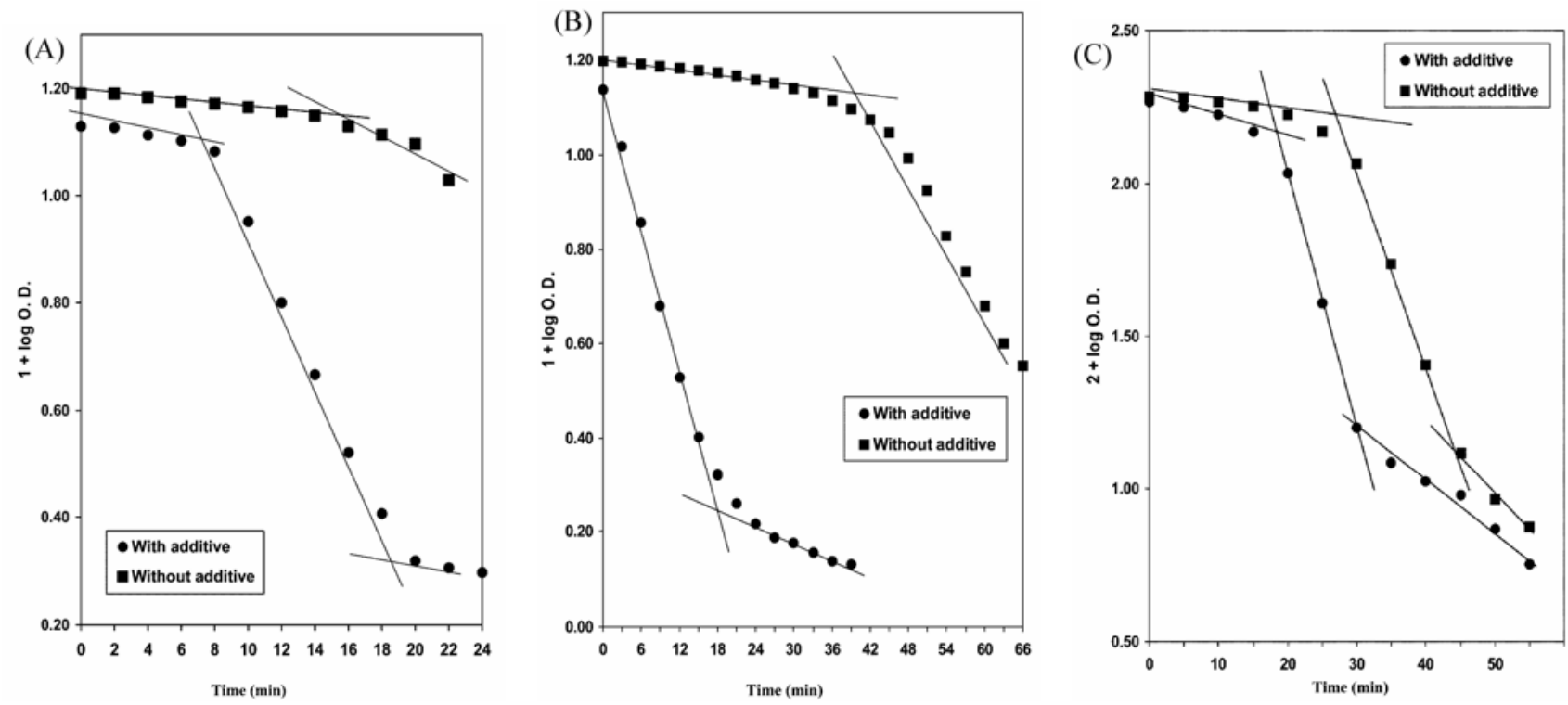

Figure 1. (A) A typical run hydroquinone system. (B) Catechol system. (C) Resorcinol system.

variation of various parameters on the rate of degradation was studied by comparing the rates of the second stage of the photo-Fenton reaction. Moreover, when the experimental conditions approach the optimum conditions, then the time taken by first stage (slow step/induction period) was found to reduce.

The organic additives accelerate the rate of reaction either by reducing the time taken in first stage i.e. ${ }^{\bullet} \mathrm{OH}$ radical generation becomes faster and/or increasing the rate of second stage. Moreover, at the optimum conditions of dye $\mathrm{FeCl}_{3} \cdot \mathrm{H}_{2} \mathrm{O}_{2}$ or additives, the rate of degradation becomes very fast and induction period was not observed in some cases.

\subsection{Effect of $p H$}

The effect of $\mathrm{pH}$ on additive catalysed photochemical degradation was investigated in the $\mathrm{pH}$ range $2 \cdot 00-5 \cdot 00$. The results are reported in table 1 . The rate of photo-Fenton degradation of phenol red was maximum at $\mathrm{pH} 2.50,3.00$, and 3.00 for hydroquinone, catechol and resorcinol system, respectively. The observations indicate that the rate of photo-Fenton reaction strongly depends on the $\mathrm{pH}$ of the system. In the system, the hydroxyl radicals are generated by reactions (7) and (9) of mechanism.

In reactions (4-5) of mechanism, $\mathrm{Fe}^{3+}$ ions are reduced to $\mathrm{Fe}^{2+}$ ions on reaction with additives. Reactions (7) and (8) also involve the reduction of $\mathrm{Fe}^{3+}$ ions to $\mathrm{Fe}^{2+}$ ions via reaction with $\mathrm{H}_{2} \mathrm{O}$ and $\mathrm{H}_{2} \mathrm{O}_{2}$, respectively. $\mathrm{Fe}^{2+}$ ions further reacts with $\mathrm{H}_{2} \mathrm{O}_{2}$ and - $\mathrm{OH}$ radicals with the regenerations of $\mathrm{Fe}^{3+}$ ions. These ${ }^{\circ} \mathrm{OH}$ radicals are involved in the photodegradation of the dye through oxidation process. At lower $\mathrm{pH}$ value $(<2.0)$ the reactions (7) and (8) are comparatively slower. As the $\mathrm{pH}$ of the medium was increased, the rate of reaction also increases because reactions ( 7 and 8$)$ of mechanism become faster. The increase in the rate continues up to $\mathrm{pH} 2 \cdot 5,3 \cdot 0$ and 3.0 for hydroquinone, catechol and resorcinol, respectively and the time taken by first stage decreased. Beyond these specific $\mathrm{pH}$ values for each additive, the reaction rate again decreases and time taken by first stage increased. This may be attributed to the retardation of reaction (9) in which $\mathrm{Fe}^{3+}$ ions are regenerated with the simultaneous formation of ${ }^{-} \mathrm{OH}$ ions.

It was observed that the $\mathrm{pH}$ of systems increases as the time of exposure increases for only those systems, which are having initial $\mathrm{pH}>4 \cdot 0$. It shows that at the higher $\mathrm{pH},{ }^{-} \mathrm{OH}$ ions are formed instead of - $\mathrm{OH}$ radicals and therefore; the rate of degradation lowers down due to less availability of hydroxyl radicals.

\subsection{Effect of hydrogen peroxide}

The effect of amount of $\mathrm{H}_{2} \mathrm{O}_{2}$ on the photochemical degradation of phenol red was also investigated. The results are reported in table 2 . The rates were determined in the range from 0.0 to $0.7 \mathrm{~mL}$. The rate of 
Table 1. Effect of $\mathrm{pH}$ on the rate of reaction.

\begin{tabular}{|c|c|c|c|c|c|c|c|c|}
\hline \multicolumn{3}{|c|}{ Hydroquinone System } & \multicolumn{3}{|c|}{ Catechol System } & \multicolumn{3}{|c|}{ Resorcinol System } \\
\hline \multicolumn{3}{|c|}{$\begin{array}{l}{\left[\mathrm{Phenol} \mathrm{Red]}=8.33 \times 10^{-5} \mathrm{M}\right.} \\
\mathrm{H}_{2} \mathrm{O}_{2}=0.2 \mathrm{~mL} \\
\mathrm{FeCl}_{3}=2.33 \times 10^{-5} \mathrm{M} \\
{\left[\text { Hydroquinone] }=2.00 \times 10^{-4} \mathrm{M}\right.} \\
\text { Light intensity }=60.0 \mathrm{~mW} \mathrm{~cm}\end{array}$} & \multicolumn{3}{|c|}{$\begin{array}{l}{[\mathrm{Phenol} \mathrm{Red}]=8.33 \times 10^{-5} \mathrm{M}} \\
\mathrm{H}_{2} \mathrm{O}_{2}=0 \cdot 1 \mathrm{~mL} \\
\mathrm{FeCl}_{3}=2 \cdot 33 \times 10^{-5} \mathrm{M} \\
{\left[\text { Catechol] }=1.67 \times 10^{-5} \mathrm{M}\right.} \\
\text { Light intensity }=60.0 \mathrm{~mW} \mathrm{~cm}{ }^{-2}\end{array}$} & \multicolumn{3}{|c|}{$\begin{array}{l}{\left[\mathrm{Phenol} \mathrm{Red]}=1.00 \times 10^{-4} \mathrm{M}\right.} \\
\mathrm{H}_{2} \mathrm{O}_{2}=0 \cdot 1 \mathrm{~mL} \\
\mathrm{FeCl}_{3}=2 \cdot 33 \times 10^{-5} \mathrm{M} \\
{\left[\text { Resorcinol] }=3.33 \times 10^{-5} \mathrm{M}\right.} \\
\text { Light intensity }=70.0 \mathrm{~mW} \mathrm{~cm}{ }^{-2}\end{array}$} \\
\hline $\mathrm{pH}$ & $\begin{array}{c}k \times 10^{3} \\
\left(\mathrm{~s}^{-1}\right)\end{array}$ & $\begin{array}{c}\text { Time } \\
\text { taken by first } \\
\text { stage (min) }\end{array}$ & $\mathrm{pH}$ & $\begin{array}{c}k \times 10^{3} \\
\left(\mathrm{~s}^{-1}\right)\end{array}$ & $\begin{array}{l}\text { Time } \\
\text { taken by first } \\
\text { stage (min) }\end{array}$ & $\mathrm{pH}$ & $\begin{array}{c}k \times 10^{3} \\
\left(\mathrm{~s}^{-1}\right)\end{array}$ & $\begin{array}{c}\text { Time } \\
\text { taken by first } \\
\text { stage (min) }\end{array}$ \\
\hline $1 \cdot 50$ & $0 \cdot 34$ & $10 \cdot 1$ & $2 \cdot 25$ & $0 \cdot 20$ & $5 \cdot 1$ & $1 \cdot 50$ & $0 \cdot 19$ & $34 \cdot 0$ \\
\hline $2 \cdot 00$ & $1 \cdot 24$ & $8 \cdot 3$ & $2 \cdot 50$ & 0.93 & $3 \cdot 8$ & $2 \cdot 00$ & $0 \cdot 26$ & $32 \cdot 3$ \\
\hline $2 \cdot 50$ & $2 \cdot 88$ & $8 \cdot 0$ & 2.75 & 1.77 & $2 \cdot 6$ & $2 \cdot 50$ & $3 \cdot 12$ & $25 \cdot 5$ \\
\hline $3 \cdot 00$ & $2 \cdot 16$ & $8 \cdot 6$ & $3 \cdot 00$ & 1.98 & $0 \cdot 0$ & $3 \cdot 00$ & $3 \cdot 34$ & $18 \cdot 0$ \\
\hline $3 \cdot 50$ & $1 \cdot 11$ & $10 \cdot 1$ & $3 \cdot 25$ & 1.93 & $1 \cdot 6$ & $3 \cdot 50$ & $3 \cdot 01$ & $31 \cdot 4$ \\
\hline $4 \cdot 00$ & $0 \cdot 58$ & $10 \cdot 4$ & $3 \cdot 50$ & $1 \cdot 61$ & $2 \cdot 4$ & $4 \cdot 00$ & 1.78 & $55 \cdot 3$ \\
\hline $4 \cdot 50$ & 0.49 & $10 \cdot 7$ & $3 \cdot 75$ & $0 \cdot 29$ & $4 \cdot 1$ & $4 \cdot 50$ & $1 \cdot 37$ & $59 \cdot 5$ \\
\hline $5 \cdot 00$ & $0 \cdot 26$ & $11 \cdot 1$ & - & - & - & - & - & - \\
\hline
\end{tabular}

Table 2. Effect of amount of hydrogen peroxide on the rate of reaction.

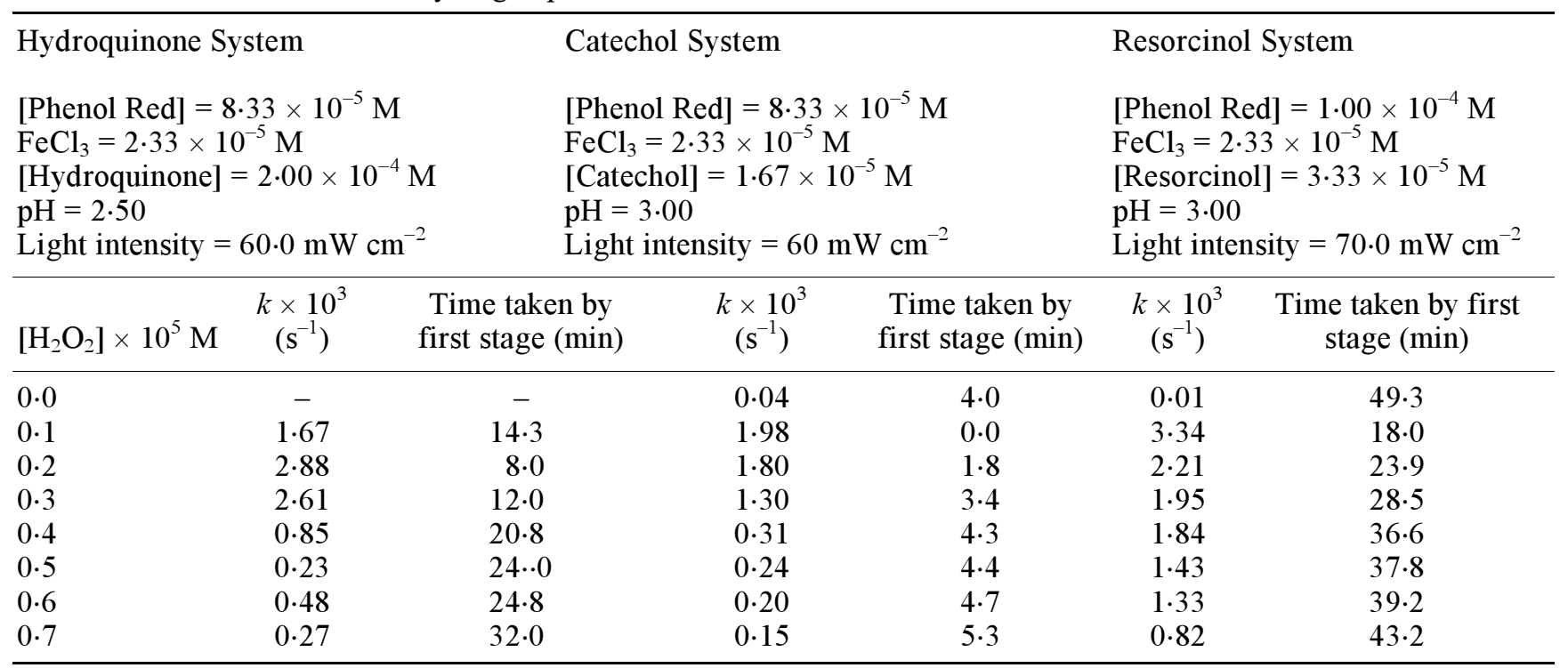

photo-Fenton degradation of phenol red was maximum at $0.2 \mathrm{~mL}, 0.1 \mathrm{~mL}$ and $0.1 \mathrm{~mL}$ for hydroquinone, catechol and resorcinol systems, respectively. Further increase in $\mathrm{H}_{2} \mathrm{O}_{2}$ concentration beyond these limits causes retardation of reaction. This may be explained on the basis that as the concentration of $\mathrm{H}_{2} \mathrm{O}_{2}$ is increased, the rate of reaction increases due to acceleration of reaction (9) of mechanism in which $\mathrm{H}_{2} \mathrm{O}_{2}$ reacts with $\mathrm{Fe}^{2+}$ ion and generates ${ }^{\circ} \mathrm{OH}$ radicals but a further increase in concentration causes the acceleration of reaction (10) in which $\mathrm{H}_{2} \mathrm{O}_{2}$ reacts with ${ }^{\circ} \mathrm{OH}$ radicals and as a consequence, a decrease in the rate of final reaction (13) has been observed.

\subsection{Effect of additives}

The effect of variation of concentration of additives on the photochemical degradation of phenol red was also investigated. The rates were determined in the range from $0.00-3.33 \times 10^{-4}$ for hydroquinone, $0.00-8.33 \times 10^{-5}$ for catechol and $0.00-2.33 \times 10^{-4}$ for resorcinol systems. 
The observed data show that rate of reaction was increased with the increase in concentration up to $2.00 \times 10^{-4}, 1.67 \times 10^{-5}$ and $3.33 \times 10^{-5} \mathrm{M}$ for hydroquinone, catechol and resorcinol, respectively. It was also observed that the time taken by first stage is decreased and at this concentration the values of induction period are 8.0, 0.0 and $18.0 \mathrm{~min}$ for hydroquinone, catechol and resorcinol, respectively. On further increase in concentration of additives, the rate of reaction decreases and the time taken by first stage is increased. The effect of aromatic additives is so important that these can significantly accelerate the Fenton reaction of phenol red even at very low concentrations. Moreover, the data show that these additives (hydroquinone, catechol and resorcinol) do not behave only as a catalyst, but also as a reactant, which were attacked by the hydroxyl radicals formed in the reaction process, and as a result, the rate of degradation decreases after maxima.

The Fenton degradation rates of phenol red with different aromatic additives is in the following order:

$$
\text { Hydroquinone }>\text { Catechol }>\text { Resorcinol. }
$$

This order is also quite consistent with their ability to be transformed into their corresponding quininelike compounds. The catalysis by additives could be attributed to their reactions with ferric ions in which ferrous ion are generated with simultaneous transformation of hydroquinones to quinones. It is difficult to oxidise resorcinol directly by ferric ion into a quinine-like compound due to its molecular structure. However, hydroxyl radicals can attack resorcinol to generate hydroxyl substituted hydroquinone, which can promote the Fenton reaction although less efficiently as compared to hydroquinone (reactions $1-3)$.

With all the additives, initial induction period was observed. At a later stages of reaction, a lag period has also been observed for resorcinol, where rate of reaction again slows down.

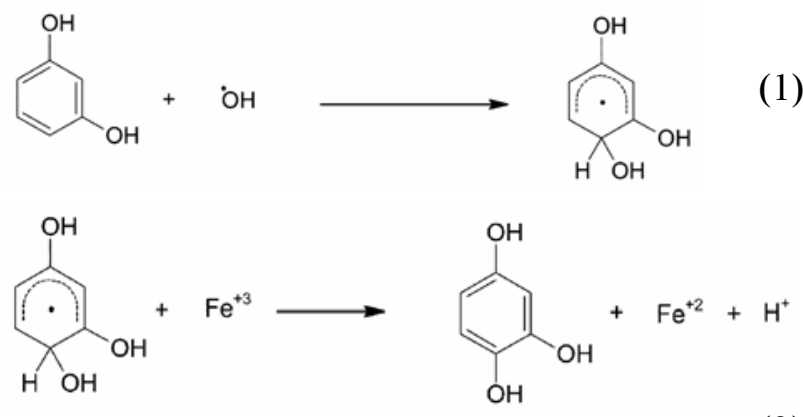

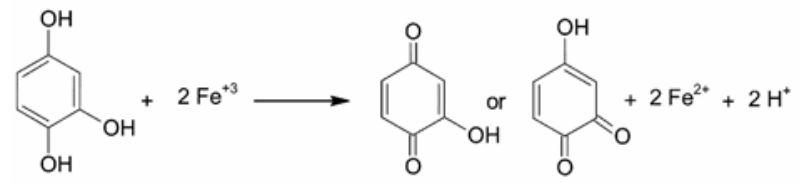

\subsection{Effect of ferric chloride concentration}

The effect of concentration of ferric ions on the rate of photochemical degradation of phenol red was observed by keeping all other factors identical. The results are summarised in table 3 . It is clear from the data that the rate of photo-Fenton degradation increases on increasing concentration of ferric chloride and the time taken by first stage decreases. The rates were determined for ferric ion concentration up to concentration $2.33 \times 10^{-5} \mathrm{M}$ for all the systems. Because beyond this concentration, the rates were extremely fast and it was not possible to record the observations correctly due to experimental limitations. This increasing trend may be explained on the basis that on increasing the concentration of ferric chloride, the concentration of $\mathrm{Fe}^{2+}$ ions increases. This results in an enhanced generation of the ${ }^{\circ} \mathrm{OH}$ radicals and as a consequence, the rate of photochemical degradation also increases.

\subsection{Effect of phenol red concentration}

The effect of phenol red concentration on the rate of its photo-Fenton degradation was observed and the results are summarized in table 4 . The rate of photoFenton degradation was found to increase with increasing concentration of phenol red up to $8.33 \times 10^{-5} \mathrm{M}, 8.33 \times 10^{-5} \mathrm{M}$ and $10.0 \times 10^{-5} \mathrm{M}$ for hydroquinone, catechol and resorcinol system, respectively. Further increase in concentration beyond these limits results in decrease in the rate of degradation. This may be explained on the basis that on increasing the concentration of phenol red, the reaction rate increases, since more molecules of dye were available for degradation. But further increase in concentration causes retardation of reaction due to increase in number of collisions between dye molecules themselves whereas probability of collisions between dye and ${ }^{\circ} \mathrm{OH}$ radicals will decrease. As a consequence, retardation in rate of reaction was observed. Unsuitable steric orientation is also one of the factors for a decrease in the rate of reaction. 
Table 3. Effect of $\mathrm{FeCl}_{3}$ concentration on the rate of reaction.

\begin{tabular}{|c|c|c|c|c|c|c|c|}
\hline \multicolumn{3}{|c|}{ Hydroquinone System } & \multicolumn{3}{|c|}{ Catechol System } & \multicolumn{2}{|c|}{ Resorcinol System } \\
\hline \multicolumn{3}{|c|}{$\begin{array}{l}{[\text { Phenol Red }]=8.33 \times 10^{-5} \mathrm{M}} \\
\mathrm{H}_{2} \mathrm{O}_{2}=0.2 \mathrm{~mL} \\
{[\mathrm{Hydroquinone}]=2.00 \times 10^{-4} \mathrm{M}} \\
\mathrm{pH}=2.50 \\
\text { Light intensity }=60.0 \mathrm{~mW} \mathrm{~cm}-2\end{array}$} & \multicolumn{3}{|c|}{$\begin{array}{l}{[\text { Phenol Red }]=8.33 \times 10^{-5} \mathrm{M}} \\
\mathrm{H}_{2} \mathrm{O}_{2}=0.1 \mathrm{~mL} \\
{[\text { Catechol }]=1.67 \times 10^{-5} \mathrm{M}} \\
\mathrm{pH}=3.00 \\
\text { Light intensity }=60.0 \mathrm{~mW} \mathrm{~cm}\end{array}$} & \multicolumn{2}{|c|}{$\begin{array}{l}{\left[\mathrm{Phenol} \mathrm{Red]}=1.0 \times 10^{-4} \mathrm{M}\right.} \\
\mathrm{H}_{2} \mathrm{O}_{2}=0 \cdot 1 \mathrm{~mL} \\
{\left[\text { Resorsinol] }=3.33 \times 10^{-5} \mathrm{M}\right.} \\
\mathrm{pH}=3 \cdot 00 \\
\text { Light intensity }=70.0 \mathrm{~mW} \mathrm{~cm}{ }^{-2}\end{array}$} \\
\hline $\begin{array}{l}{\left[\mathrm{FeCl}_{3}\right] \times} \\
\left(10^{5} \mathrm{M}\right)\end{array}$ & $\begin{array}{c}k \times 10^{3} \\
\left(\mathrm{~s}^{-1}\right)\end{array}$ & & $\begin{array}{l}\text { n by } \\
(\mathrm{min})\end{array}$ & $\begin{array}{c}k \times 10^{3} \\
\left(\mathrm{~s}^{-1}\right)\end{array}$ & $\begin{array}{l}\text { Time taken by } \\
\text { first stage (min) }\end{array}$ & $\begin{array}{c}k \times 10^{3} \\
\left(\mathrm{~s}^{-1}\right)\end{array}$ & $\begin{array}{l}\text { Time taken by first } \\
\text { stage (min) }\end{array}$ \\
\hline 0.00 & 0.016 & & & - & - & $1 \cdot 37$ & $58 \cdot 0$ \\
\hline 0.33 & $0 \cdot 16$ & & & $0 \cdot 16$ & $6 \cdot 8$ & $3 \cdot 21$ & $40 \cdot 0$ \\
\hline 0.67 & $0 \cdot 42$ & & & $0 \cdot 46$ & $3 \cdot 8$ & $2 \cdot 92$ & $30 \cdot 0$ \\
\hline 1.00 & $0 \cdot 56$ & & & 0.79 & $2 \cdot 9$ & $2 \cdot 45$ & $22 \cdot 1$ \\
\hline $1 \cdot 33$ & $0 \cdot 91$ & & & 0.99 & $2 \cdot 5$ & $2 \cdot 55$ & $20 \cdot 0$ \\
\hline $1 \cdot 67$ & $1 \cdot 23$ & & & $1 \cdot 16$ & $2 \cdot 2$ & $2 \cdot 87$ & $19 \cdot 0$ \\
\hline $2 \cdot 00$ & $2 \cdot 32$ & & & $1 \cdot 38$ & $1 \cdot 4$ & $3 \cdot 20$ & $18 \cdot 6$ \\
\hline $2 \cdot 33$ & $2 \cdot 88$ & & & 1.98 & $0 \cdot 0$ & $3 \cdot 34$ & $18 \cdot 0$ \\
\hline
\end{tabular}

Table 4. Effect of concentration of phenol red on the rate of reaction.

\begin{tabular}{|c|c|c|c|c|c|c|c|}
\hline \multicolumn{3}{|c|}{ Hydroquinone System } & \multicolumn{3}{|c|}{ Catechol System } & \multicolumn{2}{|c|}{ Resorcinol System } \\
\hline \multicolumn{3}{|c|}{$\begin{array}{l}\mathrm{H}_{2} \mathrm{O}_{2}=0.2 \mathrm{~mL} \\
\mathrm{FeCl}_{3}=2.33 \times 10^{-5} \mathrm{M} \\
{\left[\mathrm{Hydroquinone}=2.00 \times 10^{-4} \mathrm{M}\right.} \\
\mathrm{pH}=2.50 \\
\text { Light intensity }=60.0 \mathrm{~mW} \mathrm{~cm}^{-2}\end{array}$} & \multicolumn{3}{|c|}{$\begin{array}{l}\mathrm{H}_{2} \mathrm{O}_{2}=0.1 \mathrm{~mL} \\
\mathrm{FeCl}_{3}=2.33 \times 10^{-5} \mathrm{M} \\
{[\mathrm{Catechol}]=1.67 \times 10^{-5} \mathrm{M}} \\
\mathrm{pH}=3.00 \\
\text { Light intensity }=60.0 \mathrm{~mW} \mathrm{~cm}\end{array}$} & \multicolumn{2}{|c|}{$\begin{array}{l}\mathrm{H}_{2} \mathrm{O}_{2}=0.1 \mathrm{~mL} \\
\mathrm{FeCl}_{3}=2.33 \times 10^{-5} \mathrm{M} \\
{[\mathrm{Resorcinol}]=3.33 \times 10^{-5} \mathrm{M}} \\
\mathrm{pH}=3.00 \\
\text { Light intensity }=70.0 \mathrm{~mW} \mathrm{~cm}{ }^{-2}\end{array}$} \\
\hline $\begin{array}{l}{[\text { Phenol Red] } \times} \\
10^{5} \mathrm{M}\end{array}$ & $\begin{array}{c}k \times 10^{3} \\
\left(\mathrm{~s}^{-1}\right)\end{array}$ & & $\begin{array}{l}\text { en by } \\
\text { (min) }\end{array}$ & $\begin{array}{c}k \times 10^{3} \\
\left(\mathrm{~s}^{-1}\right)\end{array}$ & $\begin{array}{l}\text { Time taken by } \\
\text { first stage (min) }\end{array}$ & $\begin{array}{c}k \times 10^{3} \\
\left(\mathrm{~s}^{-1}\right)\end{array}$ & $\begin{array}{l}\text { Time taken by first } \\
\text { stage (min) }\end{array}$ \\
\hline $6 \cdot 66$ & $0 \cdot 56$ & & & 1.72 & $3 \cdot 8$ & $3 \cdot 28$ & $23 \cdot 8$ \\
\hline $8 \cdot 33$ & $2 \cdot 88$ & & & 1.98 & $0 \cdot 0$ & $2 \cdot 16$ & $22 \cdot 1$ \\
\hline $10 \cdot 00$ & 0.96 & & & $1 \cdot 56$ & $3 \cdot 2$ & $3 \cdot 34$ & $18 \cdot 0$ \\
\hline 11.66 & 0.74 & & & $1 \cdot 35$ & $3 \cdot 7$ & 1.91 & $27 \cdot 2$ \\
\hline $13 \cdot 33$ & 0.65 & & & $1 \cdot 30$ & $4 \cdot 3$ & 1.84 & $28 \cdot 9$ \\
\hline $15 \cdot 00$ & 0.64 & & & $1 \cdot 26$ & $4 \cdot 6$ & 1.81 & $31 \cdot 5$ \\
\hline $16 \cdot 66$ & $0 \cdot 47$ & & & $1 \cdot 17$ & $5 \cdot 2$ & 1.85 & $33 \cdot 2$ \\
\hline
\end{tabular}

\subsection{Effect of light intensity}

The effect of light intensity on the photo-Fenton degradation of phenol red was investigated. The results are reported in table 5. The data indicate that as the light intensity was increased the rate of reaction also increases and maximum rate of reaction for hydroquinone and catechol systems have been found at $60.0 \mathrm{mWcm}^{-2}$ and at $70.0 \mathrm{mWcm}^{-2}$ for resorcinol system. Further increase in the intensity results in a decrease in the rate of reaction may be due to thermal reactions.

\section{Mechanism}

On the basis of the experimental observations and corroborating the existing literature, a tentative mechanism has been proposed for the degradation of phenol red by photo-Fenton's reagent in the presence of aromatic additives.

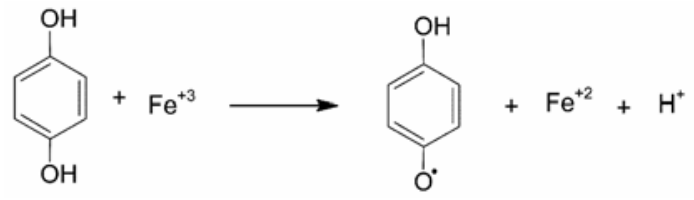


Table 5. Effect of light intensity on the rate of reaction.

\begin{tabular}{|c|c|c|c|c|c|c|c|}
\hline \multirow{2}{*}{\multicolumn{3}{|c|}{ 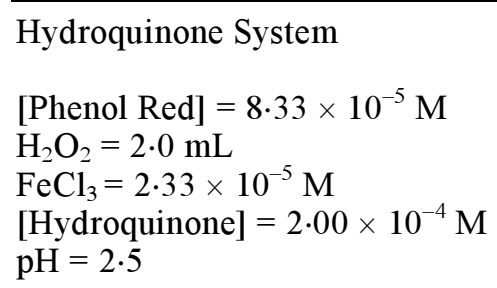 }} & \multicolumn{3}{|c|}{ Catechol System } & \multicolumn{2}{|c|}{ Resorcinol System } \\
\hline & & & \multicolumn{3}{|c|}{$\begin{array}{l}{[\mathrm{Phenol} \mathrm{Red}]=8.33 \times 10^{-5} \mathrm{M}} \\
\mathrm{H}_{2} \mathrm{O}_{2}=0.1 \mathrm{~mL} \\
\mathrm{FeCl}_{3}=2 \cdot 33 \times 10^{-5} \mathrm{M} \\
{[\text { Catechol }]=1.67 \times 10^{-5}} \\
\mathrm{pH}=3.00\end{array}$} & \multicolumn{2}{|c|}{$\begin{array}{l}{[\text { Phenol Red }]=1.00 \times 10^{-4} \mathrm{M}} \\
\mathrm{H}_{2} \mathrm{O}_{2}=0.1 \mathrm{~mL} \\
\mathrm{FeCl}_{3}=2.33 \times 10^{-5} \mathrm{M} \\
{[\text { Resorcinol }]=3.33 \times 10^{-5} \mathrm{M}} \\
\mathrm{pH}=3.00\end{array}$} \\
\hline $\begin{array}{l}\text { Light intensity } \\
\left(\mathrm{mW} \mathrm{cm} \mathrm{cm}^{-2}\right)\end{array}$ & $\begin{array}{c}k \times 10^{3} \\
\left(\mathrm{~s}^{-1}\right)\end{array}$ & & $\begin{array}{l}\text { (min by } \\
\text { (min }\end{array}$ & $\begin{array}{c}k \times 10^{3} \\
\left(\mathrm{~s}^{-1}\right)\end{array}$ & $\begin{array}{l}\text { Time taken by } \\
\text { first stage }(\mathrm{min})\end{array}$ & $\begin{array}{c}k \times 10^{3} \\
\left(\mathrm{~s}^{-1}\right)\end{array}$ & $\begin{array}{l}\text { Time taken by first } \\
\text { stage (min) }\end{array}$ \\
\hline $10 \cdot 0$ & 0.68 & & & $1 \cdot 18$ & $6 \cdot 1$ & $2 \cdot 42$ & $31 \cdot 6$ \\
\hline $20 \cdot 0$ & 0.74 & & & 1.67 & $5 \cdot 3$ & $2 \cdot 51$ & $20 \cdot 3$ \\
\hline $30 \cdot 0$ & 1.06 & & & 1.71 & $3 \cdot 7$ & 2.79 & $19 \cdot 5$ \\
\hline $40 \cdot 0$ & 1.69 & & & 1.75 & $3 \cdot 1$ & $2 \cdot 94$ & $19 \cdot 2$ \\
\hline $50 \cdot 0$ & $2 \cdot 25$ & & & 1.76 & $2 \cdot 8$ & 2.99 & $18 \cdot 9$ \\
\hline $60 \cdot 0$ & $2 \cdot 88$ & & & 1.98 & $0 \cdot 0$ & $3 \cdot 25$ & $18 \cdot 5$ \\
\hline $70 \cdot 0$ & $2 \cdot 43$ & & & 1.93 & $2 \cdot 1$ & $3 \cdot 34$ & $18 \cdot 0$ \\
\hline $80 \cdot 0$ & $2 \cdot 21$ & & & - & - & $3 \cdot 07$ & $22 \cdot 6$ \\
\hline
\end{tabular}

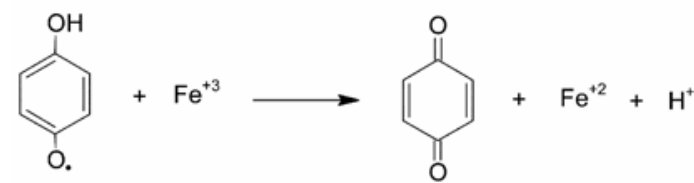<smiles>O=C1C=CC(=O)C=C1</smiles>

$$
\begin{aligned}
& \mathrm{Fe}^{3+}+\mathrm{H}_{2} \mathrm{O}_{2} \frac{h v}{\text { visible }} \mathrm{Fe}^{2+}+{ }^{\bullet} \mathrm{OH}+\mathrm{H}^{+} \\
& \mathrm{Fe}^{2+}+\mathrm{H}_{2} \mathrm{O}_{2} \frac{h v}{\text { visible }} \mathrm{Fe}^{2+}+\mathrm{HO}_{2}^{\bullet}+\mathrm{H}^{+} \\
& \mathrm{Fe}^{2+}+\mathrm{H}_{2} \mathrm{O}_{2} \rightarrow \mathrm{Fe}^{3+}+{ }^{\bullet} \mathrm{OH}+{ }^{-} \mathrm{OH} \\
& \bullet \mathrm{OH}+\mathrm{H}_{2} \mathrm{O}_{2} \rightarrow \mathrm{HO}_{2}^{\bullet}+\mathrm{H}_{2} \mathrm{O} \\
& \mathrm{Fe}^{2+}+{ }^{\bullet} \mathrm{OH} \rightarrow \mathrm{Fe}^{3+}+{ }^{-} \mathrm{OH}^{-} \\
& \mathrm{Fe}^{3+}+\mathrm{HO}_{2}^{\bullet} \rightarrow \mathrm{Fe}^{2+}+\mathrm{O}_{2}+\mathrm{H}^{+}
\end{aligned}
$$$$
\text { Dye }+{ }^{\bullet} \mathrm{OH} \rightarrow \text { Colourless degradation products }
$$

The aqueous solution of ferric ions on exposure to light generates a proton and ${ }^{\circ} \mathrm{OH}$ radicals and it is reduced to ferrous state. These ferrous ions further react with $\mathrm{H}_{2} \mathrm{O}_{2}$ producing hydroxyl ions and hydroxyl radicals and oxidised back to ferric ions. These generated hydroxyl radicals are the most probable active species in the degradation of dye.

Aromatic compounds can play an important role in catalysing the Fenton reaction, when these are transformed into hydroquinone like intermediates by the attack of ${ }^{\circ} \mathrm{OH}$ radicals. In addition, their efficiency to promote the Fenton reaction is closely related to their easiness to be transformed into hydroquinone-like intermediates. Hydroquinone-like compounds accelerate the Fenton reaction by increasing the regeneration of ferrous ion (e.g. (4), (5)), which might be the slow reaction in the mechanism of the simple Fenton reaction. Further, the hydroquinones-like compounds are continuously regenerated from quinone or semi-quinone by reacting with $\mathrm{HO}_{2}^{\circ}$ radicals and disproportion reaction, thus continuously promote the rate of reaction.

$$
\begin{aligned}
& \mathrm{HO}_{2}^{\circ}+\text { Quinone } \rightarrow \text { Semiquinone }+\mathrm{O}_{2} \\
& \mathrm{HO}_{2}^{\bullet}+\text { Semiquinone } \rightarrow \text { Hydroquinone }+\mathrm{O}_{2} \\
& 2 \text { Semiquinone } \rightarrow \text { Hydroquinone }+ \text { Quinone. }
\end{aligned}
$$

These hydroxyl radicals will degrade the phenol red. The participation of ${ }^{\circ} \mathrm{OH}$ radicals as an active oxidising species was confirmed by using hydroxyl radical scavengers, e.g. isopropanol, where the rate of photodegradation was drastically reduced. 
Further, this method has more advantages over other methods. It does not add to pollution anymore. The active oxidising species i.e. the hydroxyl radicals will dimerize to give hydrogen peroxide, which may degrade ultimately to water and oxygen.

\section{Conclusion}

photo-Fenton reactions are the most effective methods for the treatment of wastewater. In dark, the rate of Fenton reaction is slow, whereas with the irradiation of reaction mixture acceleration in the rate of degradation of dye was observed. Due to the presence of light, the rate of regeneration of ferrous ions in the system increases through the photo-Fenton reaction and this process becomes cyclic. Aromatic compounds can play an important role in catalysing the Fenton reaction. Their efficiency to promote the Fenton reaction is closely related to their tendencies to be transformed into hydroquinone-like intermediates. These aromatic additives accelerate the rate of reaction by increasing the regeneration of ferrous ions in the system. The whole process is represented diagrammatically in figure 2 .

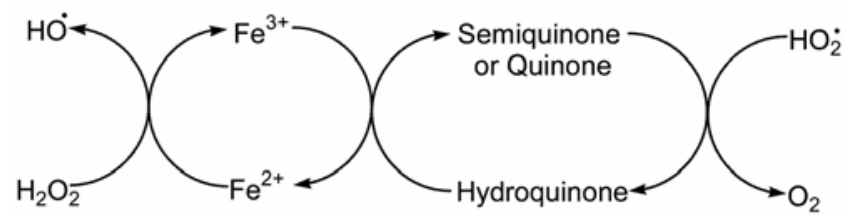

The order of efficiency of the additives in the degradation of phenol red is:

$$
\text { Hydroquinone }>\text { Catechol }>\text { Resorcinol. }
$$

\section{References}

1. Haeg W R and Yao C C D 1992 Environ. Sci. Technol. 261005

2. Spadaro J D, Zsabelle L and Ranganathan V 1994 Environ. Sci. Technol. 281389
3. Bandeara J, Morrison C, Kiwi J, Plugarin C and Pevinger P 1996 Photochem. Photobiol. A: Chem. 99 57

4. Spacek W, Bauer R and Heisler G 1995 Chemosphere 30477

5. Barb W G, Baxendale J H, George P and Hargrave K R 1951 Trans. Faraday Soc. 47591

6. Walling C 1975 Acc. Chem. Res. 8125

7. Zepp R G, Faust B C and Hoigue J 1992 J. Environ. Sci. Technol. 26313

8. Sanchez L, Peral J and Domenech X 1996 Electrochim. Acta 411981

9. Mogra D, Mehta R, Ameta R and Ameta S C $2002 \mathrm{~J}$. Indian Chem. Soc. 79593

10. Mogra D, Ameta R, Chhabra N and Ameta S C 2003 Intl. J. Chem. Sci. 1211

11. Prousek J and Duriskova I 1998 Chem. Listy. 92218

12. Goi A, Veressinina Y and Trapido M 2008 Chem. Eng. J. 1431

13. Chen F, Ma W and Zhao J 2002 J. Phys. Chem. A 106 9485

14. Sedlák P, Lunak S, Brodilová J and Lederer P 1989 Rect. Kenet. Catal. Lett. 39(2) 249

15. Walling C 1998 Acc. Chem. Res. 31155

16. Huang Y H, Huang Y-F, Chang P-S and Chen C-Y 2008 J. Hazard. Mater. 154655

17. Ameta S C, Punjabi P B, Kumari Chetna and Yasmin 2006 J. Indian Chem. Soc. 8342

18. Huang Y-H, Su H-T S and Lin L-Y 2009 J. Environ. Sci. 2135

19. Tamimi M, Qourzal S, Barka N, Assabbane A and Ait-Ichou Y 2008 Separat. Purif. Technol. 61103

20. Hermosilla D, Cortijo M and Huang C P 2009 Sci. Tot. Environ. 4073473

21. Papić S, Vujević D, Koprivanac N and Šinko D 2009 J. Hazard. Mater. 1641137

22. Ma X-J and Xia H-L 2009 J. Hazard. Mater. 162386

23. Ruppert G, Baur R and Heisler G 1993 J. Photochem. Photobiol. 73A 75

24. Figueroa S, Vázquez L and Alvarez-Gallegos A 2009 Wat. Res. 43283

25. Zakharov I V and Kumpman V V 1996 Kinet. Catal. 37174

26. Laat J D and Truong Le J 2004 Chemosphere 55715

27. Voelker B M and Sulzberger B 1996 Environ. Sci. Technol. 301106

28. Shadyro O I, Sosnovskaya A A, Edimecheva I P, Ostrovskaya N I, Kazem K M, Hryntsevich I B and Alekseev A V 2007 Bioorg. Med. Chem. Lett. 17 6383 